\title{
Smoking, health knowledge, and anti-smoking campaigns: An empirical study in Taiwan
}

\author{
Chee-Ruey Hsieh ${ }^{\text {a,* }}$, Lee-Lan Yen ${ }^{b}$, Jin-Tan Liu ${ }^{c}$, \\ Chyongchiou Jeng Lin ${ }^{\mathrm{d}}$
}

${ }^{2}$ The Institute of Economics, Academia Sinica, Nankang, Taipei, 11529, Taiwan, ROC

${ }^{b}$ Institute of Public Health, National Taiwan University, Taipei, Taiwan, ROC

${ }^{c}$ Department of Economics, National Taiwan University, and Institute of Economics, Academia Sinica, Taipei, Taiwan, ROC

${ }^{d}$ Department of Health Services Administration, Graduate School of Public Health,University of Pittsburgh, Pittsburgh, PA, 15261, USA

Received 15 April 1994; revised 15 October 1994

\begin{abstract}
This paper uses a measure of health knowledge of smoking hazards to investigate the determinants of health knowledge and its effect on smoking behavior. In our analysis, two equations are estimated: smoking participation and health knowledge. The simultaneity problem in estimating smoking behavior and health knowledge is also considered.

Overall, the estimated results suggest that anti-smoking campaigns have a significantly positive effect on the public's health knowledge, and this health knowledge in turn, has a significantly negative effect on smoking participation. The health knowledge elasticities of smoking participation are -0.48 and -0.56 for all adults and adult males, respectively.
\end{abstract}

JEL classification: II

Keywords: Smoking participation; Health knowledge; Anti-smoking campaigns

"Corresponding author. Fax: 886-2-7853946. 


\section{Introduction}

Smoking is acknowledged to be the cause of many diseases, such as lung cancer, chronic bronchitis and emphysema, and ischemic heart disease. Due to growing concerns about the external costs of the personal smoking decision and lack of consumer information on the effects of smoking on health, many developed countries have adopted a series of policies over the past thirty years to discourage cigarette smoking. These policies can be categorized into three types: (1) increasing cigarette excise taxes; (2) imposing regulations upon smoking in public places and/or private work sites, and upon advertising by cigarette manufactures; (3) providing the public with information and education on the harmful effects of cigarette smoking. Although there is controversy over what policies are most effective in reducing smoking, evidence from empirical research has suggested that such anti-smoking policies have a positive effect (Lewit et al., 1981; Wasserman et al., 1991; Sung et al., 1992; Keeler et al., 1993). For example, the percentage of male smokers in the United States dropped from $52.9 \%$ in 1964 to $33 \%$ in 1986 (Chaloupka, 1992).

Although anti-smoking campaigns have a long history and have worked successfully in most developed countries, they are only in the "infant stage" in Taiwan. The government and private organizations in Taiwan have made some efforts to discourage cigarette consumption since 1987. However, most of these efforts are limited to information policies, which are designed to increase public awareness of the harmful effects of cigarette smoking (hereafter referred to as "health knowledge").

The purpose of this paper is to empirically examine the effect of health knowledge on smoking activity in Taiwan. The focal points of this paper are: (1) to what extent do individuals have an accurate knowledge of the consequences of smoking on health; (2) what is the linkage between health knowledge and smoking behavior; (3) what are the effects of various anti-smoking campaigns on the health knowledge of consumers.

The remainder of this paper is as follows. Section 2 briefly presents the institutional features of the cigarette market and anti-smoking policies in Taiwan. Section 3 describes the data and methodology used in the analysis. Section 4 analyzes the empirical findings, and Section 5 provides the summary and conclusion.

\section{An overview of the cigarette market in Taiwan}

Cigarettes have been produced by a monopoly firm owned by the government in Taiwan since 1900. This monopolistic system was established by the Japanese during the colonial period, and was re-organized under its present name, the Taiwan Tobacco \& Wine Monopoly Bureau (TTWMB), after World War II. The 
Table 1

Market share of imported cigarettes in Taiwan, unit: case $/ 500$ packs

\begin{tabular}{llll}
\hline Year & $\begin{array}{l}\text { Total cigarettes } \\
\text { consumption }\end{array}$ & $\begin{array}{l}\text { Imported } \\
\text { cigarettes }\end{array}$ & $\begin{array}{l}\text { Market share of } \\
\text { imported cigarettes } \\
(\%)\end{array}$ \\
\hline 1986 & $3,127,976$ & 60,700 & 1.94 \\
1987 & $3,458,413$ & 611,358 & 17.68 \\
1988 & $3,447,188$ & 609,409 & 17.68 \\
1989 & $3,518,087$ & 554,096 & 15.75 \\
1990 & $3,491,397$ & 557,598 & 15.97 \\
1991 & $3,671,844$ & 621,255 & 16.92 \\
1992 & $3,633,348$ & 697,470 & 19.20 \\
\hline
\end{tabular}

Source: TTWMB (1993, p. 8).

revenue from selling cigarettes was forwarded to the Ministry of Treasury and played a very important role in government finances in the early postwar years. However, the importance of this profit has fallen year by year as the share of other tax revenues (such as personal and corporate income taxes) has increased as a result of economic growth. For example, the monopolistic profit from cigarettes comprised $17.3 \%$ of the government tax revenue in 1962. This share had fallen to $2.1 \%$ by 1992 (TTWMB, 1993, p. 1 ).

Since the government focused only on the monetary gains from selling cigarettes, the 1964 U.S. Surgeon General's Report pointing out that cigarette smoking was causally related to lung cancer did not mobilize any significant anti-smoking campaigns in Taiwan. Thus, in contrast to other developed countries, after this information "shock", cigarette consumption per adult (age 15 and older) still continued to grow. Annual cigarette consumption per adult increased by $27 \%$, from 96 packs in 1965, to 122 packs in 1991. In addition, the smoking participation rate among male adults has remained almost constant at $60 \%$ over the past two decades (TTWMB, 1991).

The growing trend of annual cigarette consumption per adult in Taiwan provides new marketing opportunities to foreign tobacco manufacturers especially when they are suffering losses from decreases in cigarette sales in most developed countries. In 1987, as a result of trade negotiations, the Taiwanese government opened the door to the import of cigarettes from the U.S. and European countries. As we can readily observe in Table 1 , before the market was opened to imports, ${ }^{2}$ the share of imported cigarettes was less than $2 \%$, but this share rapidly increased

\footnotetext{
${ }^{1}$ In Taiwan, smoking is traditionally a male habit. The smoking participation rate among female adults is only about $3 \%$ to $5 \%$. See TTWMB (1991, pp. 64-65).

${ }^{2}$ Before 1987 , the TTWMB had a monopoly power to import cigarettes from other developed countries.
} 
to $17.68 \%$ in the first year the cigarette market was opened, and grew further to $19.2 \%$ by 1992 . The rapid growth of the market share of imported cigarettes is mainly due to the following reasons: (1) the decrease in the retail price of imported cigarettes though the removal of monopolistic pricing imposed by the TTWMB; ${ }^{3}$ (2) the intensive advertising (especially targeted at youth) of imported cigarettes by foreign tobacco manufacturers; (3) the strong preference for imported cigarettes among youth.

Due to the impact of imported cigarettes, the smoking rate among young people has increased tremendously in recent years (TTWMB, 1991). Since most people started smoking in their youth (Lewit et al., 1981), the increasing smoking rate among young people has raised serious concern and has stimulated anti-smoking sentiment among the general public. Therefore, the government and many private organizations in Taiwan have taken the following concrete steps to discourage cigarette consumption.

First, beginning in 1987, the Department of Health in Taiwan required that a health warning label be placed in all cigarette advertising and on every package of cigarettes. The contents of this health warning label was further strengthened in 1992. ${ }^{4}$ Second, the government banned all cigarette advertising in radio, T.V. and newspaper media. Moreover, cigarette advertising in magazines was limited to 120 advertisements per cigarette manufacturer per year. The use of cigarette vending machines was also prohibited in Taiwan. Third, many private organizations and the government broadcast anti-smoking messages in radio, television and other mass media and provide educational programs in schools to increase public awareness of the harmful effects of cigarette smoking. ${ }^{5}$ Finally, the government has, since 1991, tried to enact a law to: (1) restrict smoking in public places; (2) ban all forms of cigarette advertising; and (3) set the minimum smoking age at 18 years. However, this anti-smoking legislation has not been passed by law-makers so far. Therefore, the current regulations on smoking areas are limited to only a few places, such as elevators and airplanes.

\footnotetext{
${ }^{3}$ The government used an excise tax to replace the monopolistic profit for imported cigarettes in 1987. The excise tax is NT $\$ 16.6$ per pack, which is equivalent to $45 \%$ of the average retail price and is lower than the monopolistic profit imposed by the TTWMB before 1987.

${ }^{4}$ The current contents of this label include the following six categories: (1) smoking is harmful to health; (2) smoking is causally related to cancers; (3) smoking is causally related to lung cancer, cardiovascular disease and emphysema; (4) smoking by pregnant women may result in premature births and low birth weight; (5) smoking is harmful to you and to others; (6) quitting smoking now greatly reduces serious risk to your health.

${ }^{5}$ For example, the total budget of the Department of Health allocated to the anti-smoking program was NT\$ 12 million in 1992, which was equal to $3.7 \%$ of govemment expenditure used in health promotion programs. In addition, other government sectors, such as the Environmental Protection Agency, also spend similar amounts of their budget on anti-smoking programs.
} 


\section{Data and methods}

\subsection{Study sample}

The data used in this study are based on a national survey of smoking behavior conducted by the Institute of Public Health, National Taiwan University (Yen et al., 1993), in early 1993. The survey was conducted on a random basis. The first step in the sampling process was to select 25 regions from Taiwan, from each of which 6 clusters were then selected. Each cluster contained 15 households. All adults aged 18 years and older in each household were interviewed in person. Overall, there were 2,437 completed survey responses, resulting in a sample of 2,433 individuals with valid observations for the key variables of interest. ${ }^{6}$ Adults in the age groups of 18-22 years old and of 23-45 years old comprised $10 \%$ and $51 \%$ of the sample, respectively, and men comprised $49 \%$ of the total (Table 2).

\subsection{Smoking behavior}

There are two measures of smoking behavior in the related literature: whether or not an individual is a current smoker (smoking participation) and the number of packs of cigarettes smoked (quantities of consumption). Only smoking participation is examined in this paper, because smoking participation is considered relatively more important than the other measure (Lewit et al., 1981, p. 555; Kenkel, 1991a, p. 296). In addition, there is evidence that survey respondents may underreport their cigarette consumption because of the social undesirability of smoking (Lewit and Coate, 1982). Therefore, the measure of cigarette consumption from survey data may be inaccurate (Lewit et al., 1981, p. 556; Wasserman et al., 1991, p. 47).

Smoking participation is represented by a binary variable (SMOKER), which equals 1 if a person currently smokes and 0 otherwise. In the data, 26\% of the respondents were smokers, and the rest were non-smokers $(70 \%)$ or former smokers (4\%) (Table 2). As mentioned in the previous section, the smoking rate among females is very low (only about $3 \%$ ) in Taiwan. Therefore, this study focuses on male smoking behavior. In the male subsample, the smoking rate is $51 \%$.

\subsection{Health knowledge}

In the literature, there are two existing approaches to measure a person's awareness of the hazards of tobacco use: (1) perception of smoking risk; (2) health knowledge. The first approach is used by Viscusi $(1990,1991)$, and emphasizes

\footnotetext{
${ }^{6}$ For a detailed description of the survey and sampling design, see Yen et al. (1993).
} 
Table 2

Variable names, definitions, and descriptive statistics

\begin{tabular}{|c|c|c|c|}
\hline \multirow[b]{2}{*}{ Variable } & \multirow[b]{2}{*}{ Definition } & \multicolumn{2}{|c|}{ Mean (standard deviation) } \\
\hline & & Full sample & $\begin{array}{l}\text { Subsample } \\
\text { (males) }\end{array}$ \\
\hline \multirow[t]{2}{*}{ Knowledge } & \multirow{2}{*}{$\begin{array}{l}\text { Number of correct responses for ten questions } \\
\text { about the health effects of smoking }\end{array}$} & $4.41(2.47)$ & $4.60(2.40)$ \\
\hline & & $0.26(0.44)$ & $0.51(0.50)$ \\
\hline Smoker & Respondent is current smoker (d.v.) ${ }^{a}$ & & \\
\hline Age $18-22$ & Respondent age $18-22$ (d.v.) & $0.10(0.30)$ & $0.09(0.29)$ \\
\hline Age $23-45$ & Respondent age $23-45$ (d.v.) & $0.51(0.50)$ & $0.50(0.50)$ \\
\hline Male & Male respondent (d.v.) & $0.49(0.50)$ & - \\
\hline School & Years of schooling completed & $8.53(4.65)$ & $9.39(4.19)$ \\
\hline Rural & Respondent lives in rural area (d.v.) & $0.75(0.44)$ & $0.75(0.44)$ \\
\hline Married & Respondent is married (d.v.) & $0.74(0.44)$ & $0.70(0.46)$ \\
\hline Disease & $\begin{array}{l}\text { Respondent has at least one of the following } \\
\text { diseases diagnosed by physicians: heart disease, } \\
\text { bronchitis, tuberculosis, emphysema, } \\
\text { stroke, diabetes, gastric ulcer, lung cancer, } \\
\text { hypertension, cirhosis of the liver, etc (d.v.) }\end{array}$ & $0.19(0.39)$ & $0.20(0.40)$ \\
\hline $\begin{array}{l}\text { Restrict smokin } \\
\text { in workplace }\end{array}$ & $\begin{array}{l}\text { gThere is restriction on smoking in the } \\
\text { respondent's workplace (d.v.) }\end{array}$ & $0.09(0.29)$ & $0.11(0.31)$ \\
\hline \multicolumn{4}{|c|}{ Attitude } \\
\hline Pro-enjoyable & $\begin{array}{l}\text { The degree of respondent's agreement with } \\
\text { the statement that "smoking is very enjoyable" } \\
\text { (from } 1 \text { as strong disagreement to } 5 \text { as } \\
\text { strong agreement) }\end{array}$ & $2.25(0.99)$ & $2.59(1.08)$ \\
\hline Pro-creative & $\begin{array}{l}\text { The degree of respondent's agreement with } \\
\text { the statement that "smoking can induce an } \\
\text { individual's creativity and inspiration" }\end{array}$ & $2.78(1.03)$ & $2.97(1.04)$ \\
\hline \multicolumn{4}{|l|}{ Anti-smoking } \\
\hline Join-activity & $\begin{array}{l}\text { Respondent joined any form of anti-smoking } \\
\text { activity (such as parade) in past one year } \\
\text { (d.v.) }\end{array}$ & $0.01(0.10)$ & $0.02(0.13)$ \\
\hline Advertising & $\begin{array}{l}\text { Respondent saw anti-smoking advertising } \\
\text { in the mass media in past three months } \\
\text { (d.v.) }\end{array}$ & $0.83(0.38)$ & $0.85(0.36)$ \\
\hline Legislation & $\begin{array}{l}\text { Respondent knew that the government } \\
\text { tried to enact a law to restrict smoking in } \\
\text { recent years (d.v.) }\end{array}$ & $0.26(0.44)$ & $0.30(0.46)$ \\
\hline Pro-regulation & $\begin{array}{l}\text { Respondent agrees with the government's } \\
\text { effort to restrict smoking in public places } \\
\text { (d.v.) }\end{array}$ & $0.89(0.32)$ & $0.86(0.35)$ \\
\hline Sample size & & 2,433 & 1,189 \\
\hline
\end{tabular}

d.v. indicates dummy variable. 
people's perceptions about the magnitude of their risk (in terms of probability) from the specific hazard of smoking (e.g. lung cancer). ${ }^{7}$ In Viscusi $(1990,1991)$, respondents were asked: "Among 100 cigarette smokers, how many do you think will get lung cancer because they smoke?" Using this measure of lung cancer risk perception, Viscusi estimates the effect of risk perception on smoking activity. The second approach is used by Kenkel (1991a), which reflects only knowledge about the existence of health hazards and does not relate to the magnitude of the risks from such hazards. Kenkel (1991a) uses the number of illnesses that the respondent correctly believed were related to cigarette smoking as a direct measure of health knowledge. ${ }^{8}$

The empirical results obtained from Viscusi $(1990,1991)$ and Kenkel (1991a) show that both risk perception and health knowledge have significant negative effects on smoking decisions. Thus, we speculate that both measures of personal awareness of smoking hazards have a positive correlation, although the direct evidence is not available so far. As we discussed in the previous section, anti-smoking campaigns in Taiwan place greater emphasis on the existence of health hazards than on the magnitude of the risk. Therefore, we use health knowledge (Kenkel's approach) to measure personal awareness of smoking hazards. ${ }^{9}$ The survey asked respondents ten multiple-choice questions about the health hazards of smoking. ${ }^{10}$ Each correct answer was given a value of 1 , each incorrect answer was given a value of 0 . Unknowns were also given a 0 value. The variable KNOWLEDGE is the sum of these values, and reflects the respondents' awareness of the harmful effects of cigarette smoking.

Since the KNOWLEDGE variable reflects the answers to ten questions, it can take values ranging from 0 (complete ignorance) to 10 (complete awareness). In this sample, the mean of KNOWLEDGE is 4.41 for the full sample and 4.60 for the male subsample (Table 2). This result suggests that public awareness of the health hazards of smoking is far from complete. People know some but not all of

\footnotetext{
${ }^{7}$ In most cases, individual risk perception is not equal to the actual risk level. This is because individuals' beliefs are a weighted average of their prior probability assessments and the risk information they have received (Viscusi, 1992a, 1992b). Also, the concepts of risk perception and attitude towards risk are different. In fact, attitude towards risk is derived from standard expected utility theory which in tum is based on the individuals' actual probability. Therefore, the relationship between attitude towards risk and risk perception will depend on the relationship between the perceived and actual probabilities. For more detailed discussions, see Smith and Desvousges (1988) and Viscusi (1992a, 1992b).

${ }^{8}$ Illnesses in question are emphysema, bladder cancer, cancer of the larynx, cancer of the esophagus, chronic bronchitis, lung cancer, and heart disease (see Kenkel, 1991a).

${ }^{9}$ On the other hand, the measure of risk perception is not available in our data set. Thus, we will not explicitly examine the linkage between risk perception and health knowledge.

${ }^{10}$ The major questions asked in the survey are the following: (1) What are the major symptoms of heavy smokers? (2) What is the ingredient in cigarettes that causes addictive behavior? (3) What is the harmful effect of smoking on pregnant women? (4) What is the harmful effect of passive smoking?
} 
Table 3

Means of health knowledge by smoking status and age

\begin{tabular}{|c|c|c|c|c|c|c|c|c|}
\hline \multirow[b]{2}{*}{ Age group } & \multicolumn{2}{|c|}{ Current smoker } & \multicolumn{2}{|c|}{ Former smoker } & \multicolumn{2}{|c|}{ Nonsmoker } & \multicolumn{2}{|c|}{ All samples } \\
\hline & $N^{\mathrm{a}}$ & Mean & $N$ & Mean & $N$ & Mean & $N$ & Mean \\
\hline Age $18-22$ & 49 & $\begin{array}{c}5.39 \\
(1.79)\end{array}$ & 2 & $\begin{array}{c}5.00 \\
(2.83)\end{array}$ & 194 & $\begin{array}{c}6.18 \\
(1.81)\end{array}$ & 245 & $\begin{array}{c}6.01 \\
(1.84)\end{array}$ \\
\hline Age $23-45$ & 337 & $\begin{array}{c}4.82 \\
(2.25)\end{array}$ & 24 & $\begin{array}{c}6.21 \\
(1.84)\end{array}$ & 889 & $\begin{array}{c}5.22 \\
(2.22)\end{array}$ & 1,250 & $\begin{array}{c}5.14 \\
(2.23)\end{array}$ \\
\hline Age $46+$ & 255 & $\begin{array}{c}3.09 \\
(2.04)\end{array}$ & 69 & $\begin{array}{c}4.17 \\
(2.35)\end{array}$ & 614 & $\begin{array}{c}2.89 \\
(2.30)\end{array}$ & 938 & $\begin{array}{c}3.04 \\
(2.26)\end{array}$ \\
\hline All samples & 641 & $\begin{array}{c}4.18 \\
(2.31)\end{array}$ & 95 & $\begin{array}{c}4.71 \\
(2.39)\end{array}$ & 1,697 & $\begin{array}{c}4.49 \\
(2.53)\end{array}$ & 2,433 & $\begin{array}{c}4.41 \\
(2.47)\end{array}$ \\
\hline
\end{tabular}

${ }^{a} N=$ number of sample observations.

Numbers in parentheses are standard deviations.

the effects of smoking on health. This result is consistent with the findings in Kenkel (1991b). Kenkel (1991b) found that 10\% of the adult public, approximately 15 million Americans, in that case, are still unaware of the relationship between smoking and heart disease, and over $60 \%$ of the adult public do not know that smoking causes cancer of the bladder.

Table 3 further shows variations in health knowledge with age and smoking status. As suggested by Viscusi (1991), there are three sources of information that affect a person's awareness of health hazards of smoking: prior belief; individual experience; and information campaigns mainly provided by the government. For younger individuals, the governmental information plays a greater role because their experience with cigarettes is lower (Viscusi, 1991). A result of this is that the adult population group is expected to have a significantly lower awareness about the health effects of smoking than the younger age group. This pattern is shown for the data in Table 3, for all samples and for each of the three smoking categories. An exception to this pattern appears in the group of former smokers in the 18-22 age group which is probably due to an insufficient number of observations. In addition, Table 3 shows that current smokers have lower awareness of the smoking hazard than former smokers and nonsmokers.

\subsection{Anti-smoking campaigns}

As mentioned earlier, anti-smoking policies can be categorized into three types. Various measures are used to measure the effectiveness of the three types of policies in the empirical literature. First, estimating the price elasticity of cigarettes is the common approach to evaluate the effect of tax policy on cigarette consumption (Lewit and Coate, 1982; Wasserman et al., 1991; Hu et al., 1992; Keeler et al., 1993). Second, the impact of anti-smoking regulations is measured by a regulation index or a set of dummy variables, which reflect the severity of 
regulation (Wasserman et al., 1991; Sung et al., 1992; Chaloupka, 1992; Keeler et al., 1993). For example, the index developed by Wasserman et al. (1991) was assigned a value ranging from 0 (no regulations) to 1 (the most restrictive regulation - restricting smoking in private work sites). Finally, a time dummy variable is used in the time series study to measure the effect of the information and health warnings on smoking during the years of the anti-smoking campaign (Schneider et al., 1981; Leu, 1984; Stavrinos, 1987).

Since most anti-smoking campaigns in Taiwan are limited to information policies, this study will focus only on the effects of such information campaigns on smoking. In addition, this study is based on individual cross-section data. Therefore, the measure of the effectiveness of anti-smoking campaigns is different from existing methods. Four dummy variables are used to capture the effects of anti-smoking campaigns. These dummy variables are the following: (1) Whether the respondent participated in any form of anti-smoking activity (such as parades, speeches, etc.) in the past year; (2) Whether the respondent agrees with the government's efforts to restrict smoking in public places; (3) Whether the respondent saw any anti-smoking advertising in the mass media in the past three months; (4) Whether the respondent knew that the government tried to enact a law to restrict smoking in recent years.

The first two dummy variables reflect the degree of the respondent's involvement in, and support of, anti-smoking campaigns. The third and the fourth dummy variables indicate whether the respondent received the messages sent by the campaigns. If the information campaigns work effectively, it is expected that people with a high degree of involvement and support for the campaigns and those who received the campaign messages will have more information on the health hazards of smoking than the rest of the public. Thus, using this set of dummy variables, we can examine whether information campaigns increase the public's awareness of the health consequences of smoking. ${ }^{11}$

\subsection{Other explanatory variables}

Socio-demographic variables collected in the survey include respondents' age, gender, education, residence, marital status, and health status (Table 2). Since

\footnotetext{
"An anonymous referee points out that we cannot directly apply these dummy variables for (epidemiological) analysis of the effectiveness of the anti-smoking interventions because our study is based on a retrospective analysis of cross-section data. In the literature, there are two types of survey designs for evaluating the effectiveness of a public information program or risk communication. The first type consists of three groups of questions in one survey: the respondents are asked first about their risk perception; then the interviewer gives information about a hypothetical situation that could affect the respondents' risk; finally, the respondents are asked what their new perceptions would be for that situation (Viscusi and O'Connor, 1984). The second type of survey consists of two follow-up surveys and provides information to respondents during the period of two surveys (Liu and Smith, 1990). Unfortunately, both designs are not available in our survey.
} 
most smokers initiate their smoking behavior in their youth, and the young are the target of most anti-smoking activities, we convert age into a categorical variable in order to investigate the effects of different age-cohorts on smoking behavior and health knowledge. Two age dummy variables are defined: ages 18-22, and 23-45. The age group of people 46 years or older is used as a reference group. ${ }^{12}$ In addition to socio-demographic variables, a dummy variable is specified as being equal to 1 if there are restrictions on smoking in the respondent's workplace ("restrict smoking in workplace'). This dummy variable is used to control the effect of regulation on cigarette smoking. Also, two variables are included to measure the respondent's attitude towards smoking. One is the degree of the respondent's agreement with the statement that smoking is very enjoyable ("proenjoyable") and the other is the degree of the respondent's agreement with the statement that smoking can stimulate his creativity and inspiration ("procreative"). Both variables are measured by indexes, which are assigned values ranging from 1 (strong disagreement) to 5 (strong agreement). ${ }^{13}$

\subsection{Econometric methods}

The major purpose of this empirical study is to examine the effect of health knowledge on smoking behavior. According to models of the demand for health inputs developed by Grossman (1972), and Rosenzweig and Schultz (1983), a cigarette is treated as a "good" that enters an individual's utility function, as well as a "health input" that enters his or her health production function. The first-order conditions from such models state that an individual maximizes his/her utility by equating the marginal utility (benefit) of cigarette consumption with the marginal costs of cigarette consumption. There are two components in the marginal costs of cigarette consumption: one is the out-of-pocket expense of purchasing cigarettes; and the other is the perception of a (negative) marginal health product of smoking. Health knowledge plays an important role in determining an individual's perception of the marginal health product of smoking. If an individual has more awareness of the health hazards of smoking, his/her perception of the marginal health product of smoking (in absolute terms) will be higher

\footnotetext{
${ }^{12}$ In Taiwan, males at 20 years old are required to participate in a two-year period of military service. Most male smokers started smoking during their military-service period. Thus, we use age 22 as first cut-off point. The choice of the second cut-off (45 years old) follows Viscusi (1991) and other demography studies.

${ }^{13}$ A disadvantage of our data is the lack of income variables. However, recent empirical evidence has suggested that the effects of income on cigarette demand is weak or even insignificant (Wasserman et al., 1991; Keeler et al., 1993). In Taiwan, the income elasticity of tobacco consumption is 0.0032 , which is estimated by a simple linear consumption function using survey data of family income and expenditure (Taiwan Provincial Government, 1993, p. 57). Therefore, the lack of an income variable in this study may not be a significant problem.
} 
than that of the average person. Hence, his/her consumption level of cigarettes will be lower or even equal to zero.

Based on the framework of these models, the smoking participation equation used to estimate person $i$ 's smoking behavior can be written as follows:

$$
\text { SMOKER }_{i}=a_{0}+a_{1} X_{1 i}+a_{2} \mathrm{KNOWLEDGE}_{i}+u_{i}
$$

where $X_{1 i}$ is a vector of variables pertaining to the determinants of the smoking decision, such as sociodemographic variables and the attitude towards smoking, $a_{j}$ $(j=0,1,2)$ is the vector of coefficients, and $u_{i}$ is a random error term.

In addition, Kenkel (1991a) has suggested that health knowledge may be endogenous. This is because (1) there may be unobserved common determinants of smoking behavior and health knowledge, and (2) the psychological phenomenon of cognitive dissonance may create a standard errors-in-variables problem or may make people change their health information sets because of their smoking activity. ${ }^{14}$ Following this concern, we will also estimate the determinants of health knowledge in this study. It is interesting to examine whether the anti-smoking campaigns can increase public awareness of the health consequences of cigarette smoking effectively. Thus, the health knowledge equation to be estimated can be written as follows:

$$
\mathrm{KNOWLEDGE}_{i}=b_{0}+b_{1} X_{2 i}+b_{2} \mathrm{SMOKER}_{i}+v_{i}
$$

where $X_{2 i}$ is a vector of variables pertaining to the determinants of health knowledge, such as sociodemographic variables and the variables representing anti-smoking campaigns, $b_{j}(j=0,1,2)$ is the vector of coefficients, and $v_{i}$ is a random error term.

To begin with, Eqs. (1) and (2) are estimated separately. Since the smoking participation rate is measured by a binary variable, Eq. (1) will be estimated using probit analysis. An ordinary least squares (OLS) regression is used to estimate Eq. (2). ${ }^{15}$ In this case, KNOWLEDGE and SMOKER are treated as exogenous in estimating Eqs. (1) and (2), respectively. Then, following Viscusi (1991), both equations are estimated together in order to take into account the simultaneity problem. For the estimation of the simultaneous equations, the procedure suggested by Maddala (1983, pp. 244-245) and Viscusi (1991) is adopted. First, the reduced-form equations of smoking participation and health knowledge are estimated by using the probit model and OLS, respectively. The smoking participation Eq. (1) is then estimated using the probit model after replacing KNOWLEDGE

\footnotetext{
${ }^{14}$ As described in Kenkel (1991a, p. 299), cognitive dissonance refers to the phenomenon where the individual attempts to reconcile his/her self-image as a smart, good person with the social-image of smoking as being a bad habit.

${ }^{15}$ The Poisson regression is an altemative method used to estimate Eq. (2) because the value of the KNOWLEDGE variable ranges from 0 to 10 . The preliminary results, not shown in the table, from the Poisson regression are similar to the OLS results.
} 
with the reduced-form estimate of KNOWLEDGE ${ }_{i}$. Finally, the health knowledge Eq. (2) is estimated by OLS after the SMOKER variable is replaced with the probit estimate of the smoking participation rate from the reduced-form SMOKER equation. ${ }^{16}$

In our analysis, both equations are identified through exclusion restriction. Since the variables representing the anti-smoking campaigns are determinants of knowledge but not direct determinants of smoking, these variables enter the knowledge equation yet do not enter the smoking equation. Similarly, the variables representing smoking attitude ("pro-enjoyable" and "pro-creative") and the variable representing regulation effect ("restrict smoking in workplace") are excluded from Eq. (2) because they are direct determinants of smoking, but not of knowledge. ${ }^{17}$

\section{Results}

The empirical results are presented in Tables 4 and 5 . Table 4 shows the coefficient estimates for the single equation model, in which Eqs. (1) and (2) are estimated separately, while Table 5 shows the coefficient estimates for the simultaneous model. ${ }^{18}$

The first and third columns of Table 4 contain results for smoking participation. As predicted, knowledge of the adverse health consequences significantly decreased smoking participation, for all adults and for males. The elasticities derived from such estimates (the responsiveness of smoking participation with respect to health knowledge) are -0.13 and -0.21 for both specifications. This result still holds when health knowledge is treated as an endogenous factor. As shown in the first and third columns of Table 5, there is an even more substantial effect of health knowledge on smoking participation. The health knowledge elasticities of

\footnotetext{
${ }^{16}$ An extra step is to calculate the correct asymptotic covariance matrixes for both structural equations. The correct asymptotic covariance matrixes for the two-stage estimates of Eq. (1) and Eq. (2) are provided by Maddala (1983, p. 245). We use LIMDEP (version 6) to estimate the model and calculate the correct asymptotic covariance matrixes.

${ }^{17}$ We thank Donald S. Kenkel for his advice on this point.

${ }^{18}$ We construct a simple Hausman (1978) test for the exogeneity of SMOKER and KNOWLEDGE variables using the contrast between the single equation model (Table 4) and the simultaneous model (Table 5). The exogenous hypothesis is rejected for the SMOKER variable in Eq. (2), but is not rejected for the KNOWLEDGE variable in Eq. (1). The result is similar for the male subsample.
}

Notes to Table 4:

$t$-statistics are in parentheses.

* * Statistically significant at $1 \%$ level (two-tail test).

* Statistically significant at 5\% level (two-tail test).

- Statistically significant at $10 \%$ level (two-tail test). 
Table 4

Regression results - single equation model

\begin{tabular}{|c|c|c|c|c|}
\hline \multirow{2}{*}{$\begin{array}{l}\text { Explanatory } \\
\text { Variables }\end{array}$} & \multicolumn{2}{|l|}{ Full sample } & \multicolumn{2}{|c|}{ Subsample (males only) } \\
\hline & $\begin{array}{l}\text { Smoking } \\
\text { (probit) }\end{array}$ & $\begin{array}{l}\text { Knowledge } \\
\text { (OLS) }\end{array}$ & $\begin{array}{l}\text { Smoking } \\
\text { (probit) }\end{array}$ & $\begin{array}{l}\text { Knowledge } \\
\text { (OLS) }\end{array}$ \\
\hline Intercept & $\begin{array}{l}-4.02^{* * *} \\
(-18.38)\end{array}$ & $\begin{array}{l}0.57^{* * *} \\
(3.04)\end{array}$ & $\begin{array}{l}-1.97^{* *} \\
(-8.78)\end{array}$ & $\begin{array}{l}0.70^{* *} \\
(2.48)\end{array}$ \\
\hline Knowledge & $\begin{array}{l}-0.038^{* *} \\
(-2.017)\end{array}$ & - & $\begin{array}{l}-0.058^{* * *} \\
(-2.77)\end{array}$ & - \\
\hline Smoker & - & $\begin{array}{l}-0.32 * * * \\
(-3.09)\end{array}$ & - & $\begin{array}{l}-0.40^{* * *} \\
(-3.51)\end{array}$ \\
\hline Age $18-22$ & $\begin{array}{l}0.26 \\
(1.54)\end{array}$ & $\begin{array}{l}0.99^{* * *} \\
(6.01)\end{array}$ & $\begin{array}{r}0.31^{*} \\
(1.66)\end{array}$ & $\begin{array}{l}1.25^{* * *} \\
(5.13)\end{array}$ \\
\hline Age $23-45$ & $\begin{array}{l}0.31^{* * *} \\
(3.27)\end{array}$ & $\begin{array}{l}0.52 * * * \\
(5.29)\end{array}$ & $\begin{array}{l}0.36 * * \\
(3.44)\end{array}$ & $\begin{array}{l}0.69^{* * *} \\
(4.99)\end{array}$ \\
\hline Male & $\begin{array}{l}1.92^{* * *} \\
(19.64)\end{array}$ & $\begin{array}{c}0.14 \\
(1.55)\end{array}$ & - & - \\
\hline School & $\begin{array}{l}-0.027^{*} \\
(-2.32)\end{array}$ & $\begin{array}{l}0.24 * * \\
(21.74)\end{array}$ & $\begin{array}{l}-0.031^{* *} \\
(-2.45)\end{array}$ & $\begin{array}{l}0.21^{* * *} \\
(12.61)\end{array}$ \\
\hline Rural & $\begin{array}{l}0.33^{* * *} \\
(3.64)\end{array}$ & $\begin{array}{l}-0.078 \\
(-0.863)\end{array}$ & $\begin{array}{l}0.29^{* * *} \\
(2.98)\end{array}$ & $\begin{array}{l}-0.076 \\
(-0.576)\end{array}$ \\
\hline Married & $\begin{array}{c}0.059 \\
(0.610)\end{array}$ & $\begin{array}{l}-0.044 \\
(-0.449)\end{array}$ & $\begin{array}{c}0.086 \\
(0.807)\end{array}$ & $\begin{array}{l}0.00005 \\
(0.000)\end{array}$ \\
\hline Disease & $\begin{array}{c}0.006 \\
(0.058)\end{array}$ & $\begin{array}{l}-0.28^{* *} \\
(-2.75)\end{array}$ & $\begin{array}{c}-0.047 \\
(-0.435)\end{array}$ & $\begin{array}{l}-0.14 \\
(-0.99)\end{array}$ \\
\hline $\begin{array}{l}\text { Restrict smoking in } \\
\text { workplace }\end{array}$ & $\begin{array}{l}-0.12 \\
(-0.88)\end{array}$ & $\begin{array}{l}- \\
-\end{array}$ & $\begin{array}{l}-0.20 \\
(-1.43)\end{array}$ & - \\
\hline Atritude & & & & \\
\hline Pro-enjoyable & $\begin{array}{l}0.67^{* * *} \\
(15.02)\end{array}$ & - & $\begin{array}{l}0.66^{* * *} \\
(13.61)^{*}\end{array}$ & - \\
\hline Pro-creative & $\begin{array}{l}0.13^{* *} \\
(2.99)\end{array}$ & - & $\begin{array}{l}0.13 \cdots \\
(2.88)\end{array}$ & - \\
\hline Anti-smoking & & & & \\
\hline Join activity & - & $\begin{array}{c}0.48 \\
(1.30)\end{array}$ & - & $\begin{array}{c}0.35 \\
(0.79)\end{array}$ \\
\hline Advertising & - & $\begin{array}{l}0.74^{* *} \\
(6.92)\end{array}$ & - & $\begin{array}{l}0.84^{* \cdots} \\
(5.35)\end{array}$ \\
\hline Legislation & - & $\begin{array}{l}0.60^{* * *} \\
(6.79)\end{array}$ & - & $\begin{array}{l}0.52^{* *} \\
(4.18)\end{array}$ \\
\hline Pro-regulation & - & $\begin{array}{l}0.95^{*} * \\
(7.76)\end{array}$ & - & $\begin{array}{l}1.09^{* * *} \\
(6.66)\end{array}$ \\
\hline$R^{2}$ & - & 0.45 & - & 0.39 \\
\hline Log-likelihood & -755.87 & -4926.40 & -621.35 & -2437.56 \\
\hline Chi-square & $1294.23^{* * *}$ & - & $405.22^{* * *}$ & - \\
\hline $\begin{array}{l}\text { Ratio of correct } \\
\text { prediction }\end{array}$ & 0.86 & - & 0.74 & - \\
\hline Sample size & 2,433 & 2,433 & 1,189 & 1,189 \\
\hline
\end{tabular}


Table 5

Regression results - simultaneous equation model

\begin{tabular}{|c|c|c|c|c|}
\hline \multirow{2}{*}{$\begin{array}{l}\text { Explanatory } \\
\text { Variables }\end{array}$} & \multicolumn{2}{|l|}{ Full sample } & \multicolumn{2}{|c|}{ Subsample (males only) } \\
\hline & Smoking & Knowledge & Smoking & Knowledge \\
\hline Intercept & $\begin{array}{l}-3.77^{* * *} \\
(-13.92)^{*}\end{array}$ & $\begin{array}{l}0.55^{* * *} \\
(2.93)\end{array}$ & $\begin{array}{l}-1.73^{* * *} \\
(-6.20)\end{array}$ & $\begin{array}{l}0.55^{* *} \\
(1.92)\end{array}$ \\
\hline Predicted knowledge & $\begin{array}{l}-0.14^{* *} \\
(-2.00)\end{array}$ & - & $\begin{array}{l}-0.16^{* *} \\
(-2.17)\end{array}$ & - \\
\hline Predicted smoker & - & $\begin{array}{l}-0.10 \\
(-0.90)\end{array}$ & - & $\begin{array}{l}-0.14 \\
(-1.20)\end{array}$ \\
\hline Age $18-22$ & $\begin{array}{l}0.36 * * \\
(1.96)\end{array}$ & $\begin{array}{l}0.98^{* * *} \\
(6.00)\end{array}$ & $\begin{array}{l}0.44^{* *} \\
(2.08)\end{array}$ & $\begin{array}{l}1.25^{* *} \\
(5.10)\end{array}$ \\
\hline Age $23-45$ & $\begin{array}{l}0.36^{* * *} \\
(3.54)\end{array}$ & $\begin{array}{l}0.51^{* * *} \\
(5.19)\end{array}$ & $\begin{array}{l}0.42 * * * \\
(3.63)\end{array}$ & $\begin{array}{l}0.67 * * \\
(4.81)\end{array}$ \\
\hline Male & $\begin{array}{l}1.94 * * * \\
(19.38)\end{array}$ & $\begin{array}{c}0.039 \\
(0.405)\end{array}$ & - & - \\
\hline School & $\begin{array}{c}0.002 \\
(0.093)\end{array}$ & $\begin{array}{l}0.24^{* * *} \\
(21.89)\end{array}$ & $\begin{array}{c}-0.007 \\
(-0.337)\end{array}$ & $\begin{array}{c}0.21^{* *} \\
(12.74)\end{array}$ \\
\hline Rural & $\begin{array}{l}0.34^{* * *} \\
(3.60)\end{array}$ & $\begin{array}{l}-0.093 \\
(-1.03)\end{array}$ & $\begin{array}{l}0.30^{* * *} \\
(2.92)^{*}\end{array}$ & $\begin{array}{c}-0.11 \\
(-0.80)\end{array}$ \\
\hline Married & $\begin{array}{c}0.059 \\
(0.606)\end{array}$ & $\begin{array}{l}-0.046 \\
(-0.473)\end{array}$ & $\begin{array}{c}0.088 \\
(0.802)\end{array}$ & $\begin{array}{l}-0.009 \\
(-0.063)\end{array}$ \\
\hline Disease & $\begin{array}{c}-0.032 \\
(-0.316)\end{array}$ & $\begin{array}{l}-0.28 * * \\
(-2.78)\end{array}$ & $\begin{array}{c}-0.073 \\
(-0.644)\end{array}$ & $\begin{array}{c}-0.15 \\
(-0.99)\end{array}$ \\
\hline $\begin{array}{l}\text { Restrict smoking } \\
\text { in workplace }\end{array}$ & $\begin{array}{l}-0.80 \\
(-0.591)\end{array}$ & - & $\begin{array}{c}-0.14 \\
(-0.94)\end{array}$ & - \\
\hline Attitude & & & & \\
\hline Pro-enjoyable & $\begin{array}{l}0.63^{* * *} \\
(12.45)\end{array}$ & - & $\begin{array}{l}0.63 * * * \\
(11.84)\end{array}$ & - \\
\hline Pro-creative & $\begin{array}{l}0.13^{* * *} \\
(3.00)\end{array}$ & - & $\begin{array}{l}0.14^{* * *} \\
(2.98)\end{array}$ & - \\
\hline Anti-smoking & & & & \\
\hline Join activity & - & $\begin{array}{c}0.52 \\
(1.39)\end{array}$ & - & $\begin{array}{c}0.40 \\
(0.89)\end{array}$ \\
\hline Advertising & - & $\begin{array}{l}0.73^{* *} \\
(6.85)\end{array}$ & - & $\begin{array}{l}0.83 \\
(5.27)\end{array}$ \\
\hline Legislation & - & $\begin{array}{l}0.61^{* * *} \\
(6.86)\end{array}$ & - & $\begin{array}{l}0.533^{* *} \\
(4.24)\end{array}$ \\
\hline Pro-regulation & - & $\begin{array}{l}0.98^{* * *} \\
(7.91)\end{array}$ & - & $\begin{array}{l}1.13 * \\
(6.66)\end{array}$ \\
\hline$R^{2}$ & - & 0.45 & - & 0.38 \\
\hline Log-likelihood & -755.84 & -4930.78 & -622.69 & -2443.04 \\
\hline Chi-square & $1294.28^{* * *}$ & - & $402.55^{* * *}$ & - \\
\hline $\begin{array}{l}\text { Ratio of correct } \\
\text { prediction }\end{array}$ & 0.86 & - & 0.74 & - \\
\hline Sample size & 2,433 & 2,433 & 1,189 & 1,189 \\
\hline
\end{tabular}

Asymptotic $t$-statistics are in parentheses.

*** Statistically significant at $1 \%$ level (two-tail test).

* * Statistically significant at 5\% level (two-tail test).

* Statistically significant at $10 \%$ level (two-tail test). 
smoking participation are -0.48 and -0.56 for the entire sample and the male subsample, respectively. The results indicate that a $10 \%$ increase in health knowledge will reduce the smoking rate by $4.8 \%$ for all adults and $5.6 \%$ for males. This is equivalent to a $1 \%$ reduction in the average smoking rate and a $3 \%$ reduction in the male smoking rate.

The effects of the other explanatory variables on smoking participation are in the expected direction. As shown in Table 4, there is an inverse U-shaped relationship of smoking participation to age, with the highest rates of smoking observed in the middle-aged group (age 23-45). Males have significantly higher rates of smoking, as do individuals who live in rural areas. The level of education is inversely related to smoking participation. This is similar to the result obtained in other studies (Kenkel, 1991a). An individual's marital and health status does not have a significant influence on his/her smoking behavior. The effect of restricting smoking in the workplace is in the expected direction but not significant. Finally, people with a more pro-smoking attitude have significantly higher probabilities of smoking. The results from the simultaneous equation estimation for the sociodemographic and smoking attitude variables are similar to those obtained in Table 4 . An exception to this is that schooling is no longer significantly associated with smoking when health knowledge is treated as an endogenous factor.

The second and fourth columns of Table 4 contain the results of health knowledge. All four dummy variables representing anti-smoking campaigns have positive coefficients in the equation of health knowledge, and three of them are statistically significant at the $1 \%$ level. The results are robust across specifications (Table 5). This finding indicates the significantly positive effect of anti-smoking campaigns on people's knowledge of the health hazards of smoking.

Based on the results obtained by the simultaneous model, Table 6 quantifies the effects of the dummy variables representing the anti-smoking campaigns on health knowledge. Compared to those who did not see anti-smoking advertising in the mass media, the predicted knowledge of the health hazards of smoking was about $20 \%$ higher for respondents who did receive anti-smoking messages through advertising. Similarly, the predicted knowledge was $14 \%$ higher for people who received anti-smoking messages through legislation campaigns. People who supported regulations on smoking in public places also have more health knowledge than the general public. The relative effects are $28 \%$ and $31 \%$ for all adults and adult males, respectively. Overall, these results suggest that the recent information campaigns conducted in Taiwan have had a significant effect on public knowledge of the health hazards involved with smoking.

As shown in Table 4, the coefficient of SMOKER has a significantly negative sign in the equation of health knowledge for both the entire sample and the male subsample. This result indicates that current smokers have a lower health knowledge, which is consistent with the findings of Viscusi (1991). A plausible explanation for this result is that current smokers refuse to learn or refuse to admit the health consequences of smoking, as suggested by the psychological theory of 
Table 6

The effects of the variables representing the anti-smoking campaigns on health knowledge

\begin{tabular}{|c|c|c|c|c|}
\hline \multirow[b]{2}{*}{ Variable } & \multicolumn{2}{|l|}{ Full sample } & \multicolumn{2}{|c|}{ Subsample (males only) } \\
\hline & $\begin{array}{l}\text { Predicted } \\
\text { knowledge }\end{array}$ & $\begin{array}{l}\text { Relative effect } \\
(\%)^{\mathrm{a}}\end{array}$ & $\begin{array}{l}\text { Predicted } \\
\text { knowledge }\end{array}$ & $\begin{array}{l}\text { Relative effect } \\
(\%)^{\mathrm{a}}\end{array}$ \\
\hline \multicolumn{5}{|c|}{$\begin{array}{l}\text { Whether respondent joined any } \\
\text { form of anti-smoking activity } \\
\text { in past one year }\left(D_{1}\right) \text { ? }\end{array}$} \\
\hline $\operatorname{No}\left(D_{1}=0\right)$ & 4.41 & - & 4.60 & - \\
\hline $\operatorname{Yes}\left(D_{1}=1\right)$ & 4.93 & 11.8 & 5.00 & 8.6 \\
\hline $\begin{array}{l}\text { Whether respo } \\
\text { advertising in } \\
\text { media in past t }\end{array}$ & & & & \\
\hline No $\left(D_{2}=0\right)$ & 3.81 & - & 3.90 & - \\
\hline $\begin{array}{l}\text { Yes }\left(D_{2}=1\right) \\
\text { Whether respo } \\
\text { govemment tri } \\
\text { restrict smokin }\end{array}$ & 4.54 & 19.2 & 4.73 & 21.4 \\
\hline No $\left(D_{3}=0\right)$ & 4.25 & - & 4.45 & - \\
\hline $\begin{array}{l}\text { Yes }\left(D_{3}=1\right) \\
\text { Whether respo } \\
\text { govemment's } \\
\text { smoking in pul }\end{array}$ & 4.86 & 14.3 & 4.98 & 11.9 \\
\hline No $\left(D_{4}=0\right)$ & 3.55 & - & 3.64 & - \\
\hline Yes $\left(D_{4}=1\right)$ & 4.53 & 27.7 & 4.77 & 31.1 \\
\hline
\end{tabular}

a Relative effect $=\left\{\left[K\left(D_{i}=0\right)-K\left(D_{i}=1\right)\right] / K\left(D_{i}=0\right)\right\} \times 100$, where $K=$ predicted knowledge, $D_{i}=i$ th dummy variable representing the anti-smoking campaigns.

cognitive dissonance (Kenkel, 1991b). However, the smoking status variable becomes insignificant in the equation of health knowledge when the current smoking status is treated as an endogenous factor (Table 5).

In addition, the effects of other explanatory variables on health knowledge are in the expected direction. The single equation estimates are similar to the results obtained by the simultaneous model. First, the youngest age group (ages 18-22) has more health knowledge than the other two age groups. This result is consistent with the findings obtained in Viscusi (1991) and supports the prediction that the youngest age group is most heavily affected by the recent information campaigns.

Second, the effect of education on health knowledge is positive and significant at the $1 \%$ level. This result indicates that education also can be an effective channel to increase public knowledge of the health hazards of smoking.

Finally, there is no significant difference in health knowledge between men and women, rural and urban residents, and people with different marital status. People with smoking-related illnesses had a significantly lower health knowledge. This result does not hold if women were excluded from the analysis. 


\section{Conclusion}

The analysis in this paper uses a direct measure of health knowledge of the harmful effects of cigarette smoking to investigate the determinants of health knowledge and its effect on smoking behavior. Overall, the estimated results indicate a significantly negative effect of health knowledge on smoking, which is consistent with previous findings (Schneider et al., 1981; Kenkel, 1991a; Viscusi, 1990, 1991). Also, the results suggest that the recent anti-smoking campaigns in Taiwan have a significantly positive effect on the public's health knowledge. Based on these empirical results, it is reasonable to conclude that information policies providing the public with information and education on the harmful effects of cigarette smoking can be effective tools to decrease the smoking participation rate.

However, this study also finds that the public's health knowledge is far from complete. This result, in combination with the fact that smoking participation rate among males in Taiwan is higher than that in most developed countries, suggests that there is still a long way to go for anti-smoking campaigns in Taiwan. Further action designed to increase public awareness of the health hazards of smoking, such as increasing the intensity of anti-smoking advertising on TV, is necessary in order to further increase the public's health knowledge.

In addition, anti-smoking campaigns cannot completely rely on information policies. This is because even though most individuals have adequate health knowledge of the health hazards of smoking, the smoking rate is still significantly high. For example, if we adopt a policy that doubles the public's health knowledge from its current level of 4.41 to 8.82 , there will be a $56 \%$ decrease in smoking participation among males, according to the estimated results. In this case, the government's efforts to educate the public will be reaching completion, but the smoking rate among males will still remain at a high level of $22 \%$. Thus, other public policies to discourage smoking (such as taxation and regulation) are necessary to reduce the smoking rate further to a significantly low level.

\section{Acknowledgements}

We wish to thank Philip Cooper, Donald S. Kenkel, and two anonymous referees for their advice and comments on earlier versions; and Lung-An Li for his significant contribution in the sampling design for this study.

\section{References}

Chaloupka, F., 1992, Clean indoor air laws, addiction and cigarette smoking, Applied Economics 24, 193-205.

Grossman, M., 1972, The demand for health: A theoretical and empirical investigation (Columbia University Press, New York).

Hausman, J.A., 1978, Specification tests in econometrics, Econometrica 46, 1251-1271. 
Hu, T.W., J. Bai, T.E. Keeler and P.G. Barnett, 1992, The impact of 1989 California major anti-smoking legislation on cigarette consumption: Three years later, Working Paper No. 92-203 (Department of Economics, University of Califomia, Berkeley).

Keeler, T.E., T.W. Hu, P.G. Barnett and W.G. Manning, 1993, Taxation, regulation, and addiction: A demand function for cigarettes based on time-series evidence, Journal of Health Economics 12, $1-18$.

Kenkel, D.S., 1991a, Health behavior, health knowledge, and schooling, Journal of Political Economy 99, 287-305.

Kenkel, D.S., 1991b, What you don't know really won't hurt you, Journal of Policy Analysis and Management 10, 304-309.

Leu, R.E., 1984, Anti-smoking publicity, taxation, and the demand for cigarettes, Journal of Health Economics 3, 101- 116.

Lewit, E.M. and D. Coate, 1982, The potential for using excise taxes to reduce smoking, Journal of Health Economics 1, 121-145.

Lewit, E.M., D. Coate and M. Grossman, 1981, The effects of government regulation on teenage smoking, Journal of Law and Economics 24, 545-569.

Liu, J.T. and V.K. Smith, 1990, Risk communication and attitude change: Taiwan's national debate over nuclear power, Joumal of Risk and Uncertainty 3, 331-349.

Maddala, G.S., 1983, Limited-dependent and qualitative variables in econometrics (Cambridge University Press, Cambridge).

Rosenzweig, M.R. and T.P. Schultz, 1983, Estimating a household productions: Heterogeneity, the demand for health inputs, and their effects on birth weight, Joumal of Political Economy 91, $723-746$.

Schneider, L., B. Klein and K.M. Murphy, 1981, Governmental regulation of cigarette health information, Journal of Law and Economics 24, 575-612.

Smith, V.K. and W.H. Desvousges, 1988, Risk perception, learning, and individual behavior, American Joumal of Agricultural Economics 70, 1113-17.

Stavrinos, V., 1987, The effects of anti-smoking campaign on cigarette consumption: Empirical evidence from Greece, Applied Economics 19, 323-329.

Sung, H.Y., T.W. Hu and T.E. Keeler, 1992, A dynamic simultaneous-equations model for cigarette consumption in the western states, Working Paper No. 92-204 (Department of Economics, University of California, Berkeley).

Taiwan Provincial Government, 1993, Report on the survey of family income and expenditure, Vol. 1, Taipei.

TTWMB, 1991, The general survey on the consumption of tobacco and wine in Taiwan, Taipei, Taiwan Tobacco \& Wine Monopoly Bureau (in Chinese).

TTWMB, 1993, Taiwan tobacco \& wine statistical yearbook, Taipei, Taiwan Tobacco \& Wine Monopoly Bureau (in Chinese).

Viscusi, W.K., 1990, Do smokers underestimate risks?, Joumal of Political Economy 98, 1253-1269.

Viscusi, W.K., 1991, Age variations in risk perceptions and smoking decisions, Review of Economics and Statistics $73,577-588$.

Viscusi, W.K., 1992a, Smoking: Making the risky decision (Oxford University Press, New York).

Viscusi, W.K., 1992b, Fatal tradeoffs: Public and private responsibilities for risk (Oxford University Press, New York).

Viscusi, W.K. and C. O'Connor, 1984, Adaptive responses to chemical labeling: Are workers bayesian decision makers?, American Economic Review 74, 942-956.

Wasserman, J., W.G. Manning, J.P. Newhouse and J.D. Winkler, 1991, The effects of excise taxes and regulations on cigarette smoking, Journal of Health Economics 10, 43-64.

Yen, L.L., H.W. Yen and L.A. Li, 1993, A study of adults' smoking behavior and their perceptions of cigarette warning labels, cigarette advertising, and anti-smoking publicity in Taiwan, Research Report No. DOH82-HP-086-3M22 (Department of Health, Taipei) (in Chinese). 